\title{
BMJ Open Impact of birth characteristics, breast feeding and vital statistics on the eruption of primary teeth among healthy infants in Saudi Arabia: an observational study
}

Kholoud Abdullah Alnemer, ${ }^{1}$ Sharat Chandra Pani, ${ }^{1}$ Alaa M Althubaiti, ${ }^{2}$ Manal Bawazeer ${ }^{3}$

To cite: Alnemer KA, Pani SC, Althubaiti AM, et al. Impact of birth characteristics, breast feeding and vital statistics on the eruption of primary teeth among healthy infants in Saudi Arabia: an observational study. BMJ Open 2017;7:e018621. doi:10.1136/ bmjopen-2017-018621

- Prepublication history for this paper is available online. To view these files, please visit the journal online (http://dx.doi. org/10.1136/bmjopen-2017018621).

Received 10 July 2017 Revised 27 October 2017 Accepted 16 November 2017

\section{CrossMark}

${ }^{1}$ Department of Preventive Dental Sciences, Riyadh Colleges of Dentistry and Pharmacy, Riyadh, Saudi Arabia ${ }^{2}$ Department of Basic Medical Sciences, College of Medicine, King Saud bin Abdulaziz University for Health Sciences/ King Abdullah International Medical Research Center, Riyadh, Saudi Arabia ${ }^{3}$ King Abdullah Specialized Children's Hospital, King Saud bin Abdulaziz University for Health Sciences/King Abdullah International Medical Research Center, Riyadh, Saudi Arabia

Correspondence to Dr Sharat Chandra Pani; sharat@riyadh.edu.sa

\section{ABSTRACT}

Objectives This study aimed to explore the impact of gender, birth weight, maternal age, type of delivery, gestational age and feeding practices on the eruption of teeth in children with no underlying medical conditions or developmental defects in their first year of life.

Design A cross-sectional observational study design was used.

Setting A primary healthcare setting in Riyadh, Saudi Arabia.

Participants All children in their first year of life attending a vaccination clinic $(n=422)$ were included in the study. Infants with chronic childhood illnesses, those who were below the 5th percentile in height or weight, infants with congenital birth defects and chronic illnesses, infants who were born preterm and low birth weight infants were excluded from the study.

Outcome measures The type of delivery, birth weight, age of mother, height and weight percentile for age (as plotted on the WHO growth chart for infants) and feeding practices were recorded by the examiner, and this was followed by a clinical examination to determine the presence or absence of each tooth. Regression models were developed to determine the effect of the different variables on the presence of primary teeth.

Results There was a significant association between the weight percentile of the child (adjusted for age) and the number of erupted primary teeth, suggesting that heavier children have an earlier eruption of teeth. No association was observed between birth weight, height percentile for age or maternal age at the time of birth and the number of erupted primary teeth. Children who were exclusively breast fed were significantly more likely to have an erupted first primary tooth earlier than non-breastfed group.

Conclusions Breast feeding and the weight of the child may have an influence on the eruption of primary teeth in the first year of life.

\section{INTRODUCTION}

The ages at which the primary teeth erupt are of great significance in relation to growth
Strengths and limitations of this study

- Used a cross-sectional design to study the impact of vital statistics, birth type and feeding characteristics on the eruption of primary teeth.

- Studied children without underlying medical conditions in order to avoid the confounding effects of underlying diseases and developmental disorders.

- Despite the lack of a cohort design, the study looked at a large sample of children.

- Although the study did not use a randomised sample, it provides an overview of the factors that influence the eruption of teeth in healthy children.

and development of the child. It has been thought that eruption of deciduous teeth plays an essential role in the proper alignment, spacing and occlusion of permanent teeth. ${ }^{1}$ Several variables have been thought to influence the eruption of the primary teeth including ethnicity, ${ }^{2}$ socioeconomic status ${ }^{3}$ and nutrition status. ${ }^{4}$ A recent genome-wide association study has shown that loci associated with height and craniofacial distances can impact the eruption of primary teeth in the first year of the child's life. ${ }^{5}$

In addition to genetic factors, environmental factors such as maternal smoking, ${ }^{6}$ height and weight of a newborn at the time of birth $^{7}$ and nutrition status have been shown to play a role in the eruption of the first primary tooth. A few reports have focused on the discerning effect of nutrition in early age of a child, including breast milk. It has been suggested that the act of breast feeding encourages proper growth of the mouth and jaw, as well as secretion of hormones for proper digestion. ${ }^{7}$ This concept has been used to suggest that breast feeding may advance the eruption of primary teeth. ${ }^{8}$ 
The relationship between ethnicity and the timing of eruption of the first primary tooth is a complicated one. While there is definite evidence to show that children from different geographic regions have different eruption patterns of the primary teeth, ${ }^{9-12}$ it is not clear how much of this difference can be attributed to ethnicity. There is some evidence from Saudi Arabia to suggest that the eruption of primary teeth in Saudi children occurs at later stage when compared with Caucasian children, ${ }^{13}$ but there has been no attempt made to study the factors that affect the eruption of the eruption pattern in the first year of life. Furthermore, data from existing longitudinal studies are often plagued by the confounding effects of socioeconomic factors, overall nutritional status and overall maternal health, which vary from country to country and can often vary between different groups within the same country. ${ }^{14-16}$

Most studies on the eruption of primary teeth in the first year of life have focused on children with underlying medical conditions or nutritional deficiencies. Little attention has been paid to the factors influencing the eruption of teeth in healthy infants. The aim of this study was to examine the possible confounding factors that affect the eruption of primary teeth in the first year of life in a population of medically healthy Saudi infants.

\section{METHODOLOGY}

\section{Study design and setting}

This study was conducted from October 2016 to March 2017 among infants (age <12 months) of parents who attended the vaccination (well baby) clinic at the King Abdullah Specialist Children Hospital, National Guard Health Affairs, Riyadh, Saudi Arabia, a publicly funded free hospital. The study design aimed to examine each child once.

\section{Ethical considerations}

Informed consent was obtained in writing from the parents of the infants.

\section{Sample size}

A power analysis for multiple regressions was applied to determine the power of the achieved sample using the G power sample size calculator (http://www.gpower. hhu.de/). The post hoc sample power was calculated for a regression model using the seven eventual predictors, namely, birth weight, weight for age (percentile), height for age (percentile), age of the mother at birth, gender of the child, type of delivery and type of feeding practice. It was observed that the final sample of 422 children when computed for an effect size of 0.05 (small effect size) and alpha of 0.05 yielded an actual power of 0.94 .

\section{Sample characteristics}

The sample was selected using non-random convenience sampling of the children attending the vaccination (wellbaby) clinic of the hospital. This was a publicly funded free clinic that was responsible for providing vaccinations for children without underlying medical conditions. The sample included all children aged below 12 months who were deemed to be medically fit. The sample excluded infants with congenital birth defects, chronic illnesses, infants who were born preterm and low birth weight infants (children with birth weight below $2500 \mathrm{~g}$ ). All children who met the inclusion criteria were included in the final analysis.

\section{Data collection}

All children in the sample were seen only once except for the children who were examined for the purpose of calibration $(n=20)$. Demographic data of the family including date of birth, gender, number of siblings, rank in the family and socioeconomic data were recorded in Arabic by the parent. Data on the age of the parents at the time of birth, type of delivery (vaginal or caesarian section), twining (yes/no; if yes, identical/not identical), type of delivery (normal/caesarian section) and feeding practices (breast feeding/breast+bottlefeeding/bottle feeding only) were recorded by one of the investigators (AKA) after interviewing the parents. The birth weight of the child was obtained from the medical records of the child.

The height (in $\mathrm{cm}$ ) and weight (in $\mathrm{kg}$ ) of the child were obtained from the record made on the day of the examination. The height and weight were then transformed into a percentile value for age using the WHO standards for infant growth. ${ }^{17}$

All intraoral examinations were conducted by a single examiner (KAA) who was calibrated using the WHO criteria for an erupted tooth. Natal and neonatal teeth were not included in the analysis of teeth present in order to avoid a skew in the age of tooth eruption. For the purpose of this study, an erupted tooth was defined as any tooth with any part of its crown penetrating the gingiva and visible in the oral cavity. The examiner was calibrated for intraexaminer variability by re-examining 20 children after a gap of 2 weeks and applying the kappa statistic. The recall examinations showed low intraexaminer variability $(\mathrm{kappa}=0.925)$.

The intraoral examination was conducted in the vaccination clinic with the child placed in the mother's lap and examined using the knee-to-knee position. The oral cavity was examined with a mouth mirror and using a headlamp without the use of radiographs.

\section{Statistical analysis}

Data obtained were coded, entered in and analysed using SPSS V.22.0. Descriptive and inferential statistical analysis was performed. Descriptive analysis was used to describe the data. Mean $\pm \mathrm{SD}$ was used to describe parametric continuous variables and median (IQR for non-parametric continuous data). Categorical variables were described using frequency and percentage. The t-test was used to compare mean age between males and females. Linear regression model developed to examine 
Table 1 Demographic data and vital statistics of the study population

\begin{tabular}{|c|c|c|c|c|}
\hline & $\mathbf{N}$ & $\%$ & Mean & SD \\
\hline \multicolumn{5}{|l|}{ Gender } \\
\hline Male & 206 & 48.8 & & \\
\hline Female & 216 & 51.2 & & \\
\hline \multicolumn{5}{|l|}{ Type of delivery } \\
\hline Normal & 291 & 69.0 & & \\
\hline Caesarian section & 131 & 31.0 & & \\
\hline Assisted vaginal & 0 & 0.0 & & \\
\hline \multicolumn{5}{|l|}{ Type of feeding } \\
\hline Breast feeding only & 90 & 21.3 & & \\
\hline Breast feeding+bottle feeding & 212 & 50.2 & & \\
\hline Bottle feeding only & 120 & 28.4 & & \\
\hline Birth weight (kg) & & & 3.1 & 0.4 \\
\hline Height (cm) & & & 65.9 & 6.7 \\
\hline $\begin{array}{l}\text { Mean WHO height percentile for } \\
\text { age }\end{array}$ & & & 27.80 & 23.84 \\
\hline Weight (kg) & & & 7.6 & 1.8 \\
\hline $\begin{array}{l}\text { Mean WHO weight percentile for } \\
\text { age }\end{array}$ & & & 40.01 & 30.36 \\
\hline
\end{tabular}

the total number of teeth present as the dependent variable. Binary logistic regression models were developed to examine the different factors affecting the presence or absence of teeth. A P value $<0.05$ was considered statistically significant for all tests.

\section{RESULTS}

The study sample comprised 422 children aged between 1 day and 12 months of age with a mean age of 7.2 months and SD of 3.45. The sample comprised 206 males (48.8\%) and 216 females $(51.2 \%)$. There was no significant difference in the mean age of the male (7.2 months \pm 3.1 month) and female (7.2 months \pm 3.4 months) subjects $(\mathrm{t}=0.131$, $\mathrm{P}=0.904$ )

When the other demographic factors were tabulated, it was observed that the mean age of the fathers at the time of delivery was 35.2 years $( \pm 7.8$ years $)$ and the mothers was 30.7 years $( \pm 6.07)$. A total of 291 children in this sample were born by normal vaginal delivery, while 131 children were born by caesarian section. The height and weight of the population were converted into the percentile for age using the WHO standards. The height and weight characteristics are summarised in table 1 .

When the feeding characteristics of the population were documented, it was observed that only 90 children were exclusively breast fed. Most of the children $(n=212)$ had received a combination of breast feeding and bottle feeding, while 120 children had never been breast fed (table 1).

A chart showing the percentage of children with an erupted tooth at each given age was developed. It was observed that by the end of the first year, over $98.7 \%$ of the children had at least one erupted tooth. A percentage of 98.1 of the sample had a lower central incisor, $82.1 \%$ had an upper central incisor, $49.2 \%$ had an upper lateral incisor and only $18.5 \%$ had a lower lateral incisor erupted in the oral cavity. Natal and neonatal teeth were not included in the tabulation of the figure (figure 1).

The gender of the child, age of the mother at the time of birth of the child, the type of delivery, the number of siblings and the order of birth were placed in a linear regression model with the total number of teeth in the oral cavity as a dependent variable. There was a significant association $(\mathrm{P}<0.001)$ between the gender of the

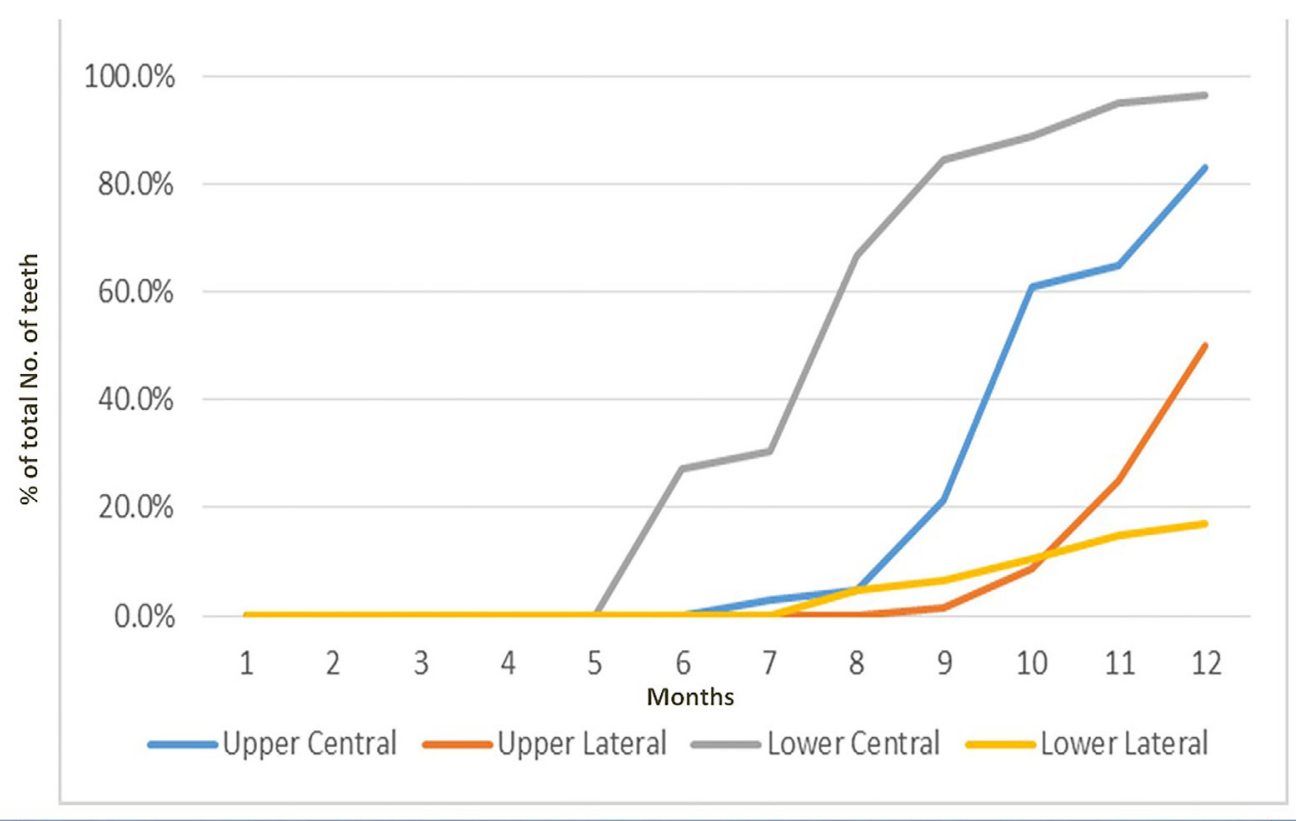

Figure 1 Percentage of the population with erupted teeth. 
Table 2 Effect of gender, birthing and familial factors on the eruption of primary teeth

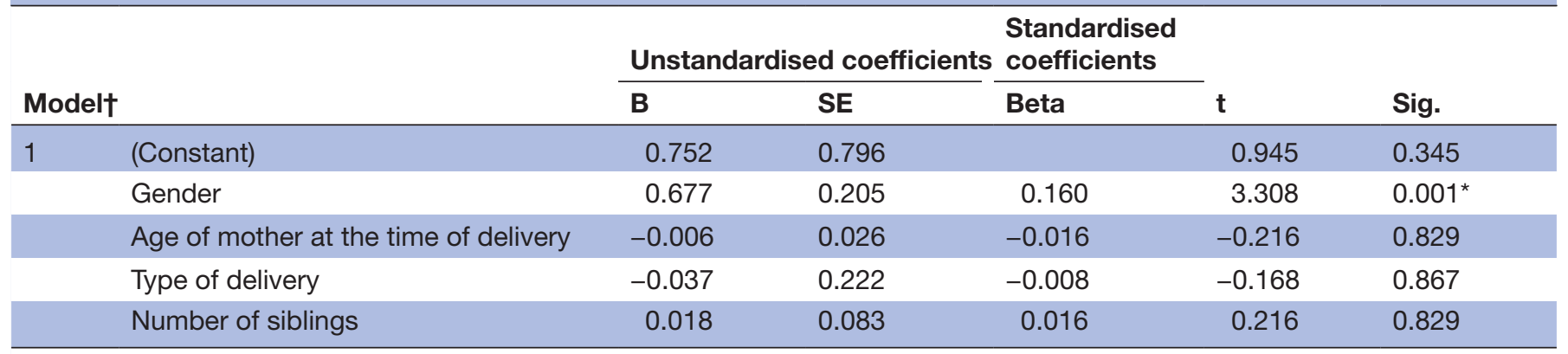

*Association significant at $\mathrm{P}<0.05$; regression indicates significantly earlier eruption in females.

†Dependent variable: total number of teeth present in the oral cavity.

child and the total number of emerged teeth with females having significantly more erupted than their male counterparts. The model showed no significant association between the age of the mother at the time of the child's birth, the number of siblings or the order of birth and the number of primary teeth in the oral cavity of the infant (table 2).

The height percentile, weight percentile and birth weight were placed in a linear regression model with the total number of teeth in the oral cavity as the dependent variable. It was observed that while the height percentile and birth weight had no significant relationship with the number of teeth in the oral cavity, there was a significant positive relationship between the weight percentile and number of teeth in the oral cavity suggesting that heavier children were likely to have more erupted teeth in the first year of life (table 3).

Children were categorised into those exclusively breast fed up to 6 months and those who were not exclusively breast fed. This factor was compared with the presence or absence of a tooth in the oral cavity. It was observed that overall children who were exclusively breast fed were significantly more likely to have an erupted primary tooth. When the model was further split according to months, it was observed that this observation was only significant up to the 8th month of life, following which there was no significant impact of breast feeding on the number of erupted teeth (table 4).

\section{DISCUSSION}

While there have been studies that have looked extensively on the timing of eruption of primary teeth and individual factors that influence the eruption of these teeth, there have been few studies that have focused on the relationship between the different factors. ${ }^{14-16}$ There is little data on the subject from the Middle East, and this study aimed to address that gap. Many studies examining the eruption of teeth have looked at the eruption time of the teeth in a single cohort over a period of time. ${ }^{9-1116}$ While this cohort model has the advantage of following a single child over a time period, it is susceptible to memory bias as it relies on the mother to recall when the particular tooth erupted. In this study, we chose a cross-sectional study design that focused on the presence or absence of a particular tooth and a single examination of the child.

The pattern observed in our study was similar to the pattern of eruption observed by other researchers. The lower central incisor was the first to erupt followed by the upper central incisors. While it is difficult to differentiate between the upper and lower teeth in the sequence of eruption, our study confirmed the previously observed sequence of central incisor followed by the lateral incisors. ${ }^{18}$ The fact that this study only focused on the first year of life meant that we had inadequate data to comment on the eruption timing and pattern of the canines and molars.

Table 3 Effect of height, weight and birth weight on the eruption of teeth

\begin{tabular}{|c|c|c|c|c|c|c|}
\hline \multirow[b]{2}{*}{ Mod } & & \multicolumn{2}{|c|}{ Unstandardised coefficients } & \multicolumn{2}{|c|}{$\begin{array}{l}\text { Standardised } \\
\text { coefficients }\end{array}$} & \multirow[b]{2}{*}{ Sig. } \\
\hline & & B & SE & Beta $\neq$ & $\mathbf{t}$ & \\
\hline \multirow[t]{4}{*}{1} & (Constant) & 0.926 & 0.732 & & 1.265 & 0.206 \\
\hline & Height percentile† & 0.000 & 0.005 & -0.003 & -0.058 & 0.954 \\
\hline & Weight percentile† & 0.017 & 0.004 & 0.236 & 4.469 & $0.000^{*}$ \\
\hline & Birth weight $(\mathrm{kg})$ & 0.005 & 0.238 & 0.001 & 0.021 & 0.983 \\
\hline
\end{tabular}

Dependent variable: total number of primary teeth.

*Suggests significant positive $(\mathrm{P}<0.05)$ indicating that heavier children of the same age will have more erupted teeth than their lighter counterparts.

†Height and weight are calculated as the percentile for age using the WHO criteria.

$\ddagger$ Positive beta indicates positive association with the variable. 
Table 4 Relationship between breast feeding and eruption of primary teeth

\begin{tabular}{llllll}
\hline Age in months & B十 & SE & df & P value & Exp(B) \\
\hline$<7.0$ & -1.922 & 0.926 & 1 & $0.018^{*}$ & 0.146 \\
\hline 8.0 & -1.021 & 1.049 & 1 & $0.032^{*}$ & 0.234 \\
9.0 & 1.466 & 0.989 & 1 & 0.138 & 4.333 \\
10.0 & 1.426 & 1.389 & 1 & 0.188 & 3.567 \\
11.0 & 1.266 & 1.089 & 1 & 0.238 & 5.333 \\
12.0 & 1.403 & 1.245 & 1 & 0.260 & 4.067 \\
Overall & 1.888 & 0.304 & 1 & 0.000 & 6.608 \\
\hline
\end{tabular}

*Association significant at $\mathrm{P}<0.05$.

†Variable(s) entered on step 1: child exclusively breast fed or not. $\ddagger$ Calculated using a binomial regression.

Sexual dimorphism has been extensively studied previously with the traditional view stating that girls generally showed an earlier eruption of teeth than boys. ${ }^{9} 19$ Our results support the conventional view and are in contrast to other studies that have found no gender difference in the timing of eruption of primary teeth. ${ }^{1120-23}$

Previous literature has shown a relationship of malnourishment to failure to thrive and the delayed eruption of teeth. ${ }^{24-27}$ The fact that the number of erupted teeth in our study was significantly associated with the weight of the child seems to suggest that even among children who are not malnourished nutritional status may be an important factor affecting the emergence of the primary teeth. Interestingly, we found no association between the birth weight of the child and the timing of eruption of the first primary tooth. This in contrast to Ntani $e t a l,{ }^{28}$ who found birth weight to be associated with the emergence of the primary dentition, with heavier babies showing earlier eruption patterns. However, it must be remembered that the current study focused only on healthy children and malnourished children were not included in the sample.

It is usually accepted that teeth emerge into the oral cavity only after the 6th month of life. However, teeth may erupt earlier ${ }^{5-8}$ due to a variety of factors. Natal teeth are teeth present at birth, while neonatal teeth are teeth that emerge within the first 4 weeks of the child's life. ${ }^{19}$ In this study, natal and neonatal teeth were excluded from analysis to prevent the possibility of skewed data.

There is a growing strong interest in the role of breast feeding on the emergence of the first primary tooth. ${ }^{8}$ It has been hypothesised that early sucking activity influences the growth of the craniofacial complex. ${ }^{29}$ It has been proposed that breast feeding is the ideal stimulus for the physiological development of both the muscular and skeletal components of the orofacial complex. ${ }^{30}$ This study seems to support the hypothesis and suggest a positive relationship between breast feeding and the emergence of the first permanent tooth. However, the absence of a relationship between the number of teeth present and the feeding status in older children suggests that more research is needed into the possible impact of breast feeding on the emergence of subsequent teeth.

The findings regarding breast feeding and tooth eruption have been reported in studies from the $\mathrm{USA}^{29}$ and Italy. ${ }^{30}$ The results of this study suggest that the role of breast feeding would seem to be a general finding that goes beyond nationality or ethnicity. This study however is focused on medically fit children born at term. Its results cannot be compared with those of studies that have examined the role of malnutrition, preterm delivery or the overall medical status of children on the eruption of the first primary tooth.

This study used a cross-sectional design rather than a longitudinal design that followed children from birth. ${ }^{91017}$ One of the limitations of the cross-sectional study design is memory recall bias, where the mother cannot accurately recall the age of eruption of the tooth. The cross-sectional design cannot be used to accurately predict the age of eruption; however, it must be remembered that the aim of this study was to look at the associated factors and not the actual age of eruption. Furthermore, by only selecting healthy children, this study aimed to remove confounding factors such as malnutrition or chronic illness.

\section{CONCLUSIONS}

Within the limitations of this study, we can conclude that there seems to be a positive association between breast feeding and the emergence of the first primary tooth. The weight (percentile for age) of the child is strongly associated with the emergence of primary teeth in the first year of life of healthy infants, and heavier children are likely to have more erupted teeth for a given age than their lighter counterparts. The results of this study indicate that factors such as the height (percentile for age) of the child, birth weight of the child, maternal age or order of birth do not seem to influence the emergence of primary teeth in healthy infants.

Acknowledgements The authors are grateful to the King Abdullah International Medical Center, Riyadh Saudi Arabia for funding the publication of this study.

Contributors SCP and KA conceptualised and designed the study. KAA and MB were responsible for collection of data, and AMA and SCP were responsible for analysis of the data. All the authors contributed equally to the preparation of the manuscript.

\section{Competing interests None declared.}

Ethics approval Ethical approval for the conduct of this study was obtained from the Institutional Review Board of the Riyadh Colleges of Dentistry and Pharmacy (FPGRP/43535005/41) and approved by the IRB of King Abdullah International Medical Research Center (SP16/224/R).

Provenance and peer review Not commissioned; externally peer reviewed. Data sharing statement № additional data available.

Open Access This is an Open Access article distributed in accordance with the Creative Commons Attribution Non Commercial (CC BY-NC 4.0) license, which permits others to distribute, remix, adapt, build upon this work non-commercially, and license their derivative works on different terms, provided the original work is properly cited and the use is non-commercial. See: http://creativecommons.org/ licenses/by-nc/4.0/ 
(c) Article author(s) (or their employer(s) unless otherwise stated in the text of the article) 2017. All rights reserved. No commercial use is permitted unless otherwise expressly granted.

\section{REFERENCES}

1. Sajjadian N, Shajari H, Jahadi R, et al. Relationship between birth weight and time of first deciduous tooth eruption in 143 consecutively born infants. Pediatr Neonatol 2010;51:235-7.

2. Tanguay R, Demirjian A, Thibault HW. Sexual dimorphism in the emergence of the deciduous teeth. J Dent Res 1984;63:65-8.

3. Enwonwu CO. Influence of socio-economic conditions on dental development in Nigerian children. Arch Oral Biol 1973;18:95-107.

4. Al-Othman AM, Saeed AA, Bani IA, et al. Mothers' practices during pregnancy, lactation and care of their children in Riyadh, Saudi Arabia. Saudi Med J 2002;23:909-14.

5. Pillas D, Hoggart CJ, Evans DM, et al. Genome-wide association study reveals multiple loci associated with primary tooth development during infancy. PLoS Genet 2010;6:e1000856.

6. Rantakallio P, Mäkinen $\mathrm{H}$. Number of teeth at the age of one year in relation to maternal smoking. Ann Hum Biol 1984;11:45-52.

7. Garn SM, Nagy JM, Sandusky ST, et al. Economic impact on tooth emergence. Am J Phys Anthropol 1973;39:233-7.

8. Oziegbe EO, Adekoya-Sofowora CA, Esan TA, et al. Breastfeeding pattern and eruption of primary teeth in Nigerian children. Pediatric Dental Journal 2010;20:1-6.

9. Magnússon TE. Emergence of primary teeth and onset of dental stages in Icelandic children. Community Dent Oral Epidemiol 1982;10:91-7.

10. Holman DJ, Jones RE. Longitudinal analysis of deciduous tooth emergence: II. Parametric survival analysis in Bangladeshi, Guatemalan, Japanese, and Javanese children. Am J Phys Anthropol 1998;105:209-30.

11. Holman DJ, Jones RE. Longitudinal analysis of deciduous tooth emergence: III. Sexual dimorphism in Bangladeshi, Guatemalan, Japanese, and Javanese children. Am J Phys Anthropol 2003;122:269-78.

12. Townsend N, Hammel EA. Age estimation from the number of teeth erupted in young children: an aid to demographic surveys. Demography 1990;27:165-74.

13. Al-Jasser NM, Bello LL. Time of eruption of primary dentition in Saudi children. J Contemp Dent Pract 2003;4:65-75.
14. Psoter WJ, Reid BC, Katz RV. Malnutrition and dental caries: a review of the literature. Caries Res 2005;39:441-7.

15. Ramos SR, Gugisch RC, Fraiz FC. The influence of gestational age and birth weight of the newborn on tooth eruption. J Appl Oral Sci 2006;14:228-32.

16. Warren JJ, Fontana M, Blanchette DR, et al. Timing of primary tooth emergence among U.S. racial and ethnic groups. J Public Health Dent 2016;76:259-62.

17. Tudehope D, Gibbons K, Cormack B, et al. Growth monitoring of low birthweight infants: what references to use? J Paediatr Child Health 2012;48:759-67.

18. Liversidge H. 4 Variation in modern human dental development. Cambridge: Patterns of growth and development in the genus Homo, 2003;37:73.

19. Kitamura S. A study on the time and order of eruption of human teeth II (in Tokyo, Japan). Shikwa gakuho 1942;47:352-68.

20. Enwonwu CO. Influence of socio-economic conditions on dental development in Nigerian children. Arch Oral Biol 1973;18:95-IN15.

21. McGregor IA, Thomson AM, Billewicz WZ. The development of primary teeth in children from a group of Gambian villages, and critical examination of its use for estimating age. Br J Nutr 1968;22:307-14.

22. Roche AF, Barkla DH, Maritz JS. Deciduous eruption in Melbourne children. Aust Dent J 1964;9:106-8.

23. JIN YUN D. Eruption of primary teeth in Korean rural children. Am J Phys Anthropol 1957;15:261-8.

24. Reddy VR. Eruption of deciduous teeth among the children of Gulbarga, South India. Indian J Med Res 1981;73:772-81.

25. Delgado $\mathrm{H}$, Habicht JP, Yarbrough $\mathrm{C}$, et al. Nutritional status and the timing of deciduous tooth eruption. Am J Clin Nutr 1975;28:216-24.

26. Truswell A, Hansen D. Eruption of deciduous teeth in protein-calorie malnutrition. J Trop Pediatr 1973;19:214-6.

27. Robinow M, Richards T, Anderson M. The eruption of deciduous teeth. In: Growth. 1942;6.

28. Ntani G, Day PF, Baird J, et al. Maternal and early life factors of tooth emergence patterns and number of teeth at 1 and 2 years of age. J Dev Orig Health Dis 2015;6:299-307.

29. Palmer B. The influence of breastfeeding on the development of the oral cavity: a commentary. J Hum Lact 1998;14:93-8.

30. Viggiano D, Fasano D, Monaco G, et al. Breast feeding, bottle feeding, and non-nutritive sucking; effects on occlusion in deciduous dentition. Arch Dis Child 2004;89:1121-3. 